\title{
A questão fundiária brasileira no desenho das políticas nacionais de habitação: considerações a partir do início do século XXI
}

The Brazilian land issue in the design of the national housing policies: considerations from the beginning of the 21 st century onwards

Tomás Antonio Moreira Joana Aparecida Z. M. T. Ribeiro

\begin{abstract}
Resumo
O Brasil evidenciou nas últimas décadas importantes transformações no campo da política urbana e habitacional. 0 contexto institucional criado sinalizou uma perspectiva promissora para articular a questão fundiária à política habitacional. Apesar de haver um consenso de que a terra urbana é componente e condição essencial para o êxito das ações que efetivam tal política, as práticas habitacionais empreendidas raramente trataram desse componente de maneira adequada. Este artigo analisa como a questão fundiária é colocada no desenho das políticas nacionais de habitação. Analisa-se a abordagem da questão fundiária na Política Nacional de Habitação, seus pressupostos e as contradições geradas ao tentar compatibilizar seu protagonismo com a aceleração do crescimento econômico do país.

Palavras-chave: política fundiária; política nacional de habitação; Programa Minha Casa Minha Vida.
\end{abstract}

\begin{abstract}
Brazil has experienced significant changes in recent decades in the field of urban and housing policy. The institutional context created signaled a promising perspective to articulate the land issue to housing policy. Although there is a consensus that urban land is component and an essential condition for the success of the actions that concretize such a policy, housing practices undertaken rarely deal with this component in the proper way. This paper examine how the land issue is inserted in the design of national housing policies. The work analyzes the approach of land issue in National Housing Policy, its purposes and the contradictions generated to match its role with the acceleration of economic growth.
\end{abstract}

Keywords: land policy, national housing policy, Program Minha Casa Minha Vida. 


\section{Introdução}

Nas últimas décadas, o Brasil assistiu a importantes transformações jurídico-institucionais no campo das políticas urbana e habitacional, cujo discurso intencionava reverter os graves problemas da polarização e segregação socioespacial intrínsecas ao padrão de desenvolvimento urbano do país. Tais problemas estiveram intimamente relacionados à questão fundiária, uma vez que a limitação do acesso ao solo para a população de baixa renda constituiu uma das principais formas de exclusão social e de consolidação da precariedade urbana e habitacional nas cidades (Bonduki, 2011; Moreira, 2012).

A Constituição Federal de 1988 e o Estatuto da Cidade de 2001 (Lei Federal 10.257/2001) instituíram um importante marco para a política urbana, ao reconhecer o direito à cidade e à moradia como princípios sociais fundamentais. Estabeleceram novos mecanismos e instrumentos urbanísticos para planejar o desenvolvimento das cidades, objetivando viabilizar os direitos referidos e criar canais de participação que pudessem mediar as relações e decisões estabelecidas entre o Estado e os agentes envolvidos no processo de produção do espaço urbano (Santos Jr. e Montandon, 2011).

A Constituição Federal, de 1988, buscou alavancar um processo de descentralização das competências governamentais, a partir do qual os municípios passaram a assumir autonomia na definição, condução e execução de suas políticas públicas. Ela também reafirmou o princípio da função social da propriedade, sob o qual o Estatuto da Cidade passou a se apoiar, definiu diretrizes para seu cumprimento e estabeleceu o Plano Diretor municipal como instrumento básico dos conteúdos da política urbana (ibid., 2011).

A criação do Ministério das Cidades e a composição de secretarias nacionais, a partir de 2003, permitiram institucionalizar novas políticas, voltadas à construção de um pacto para enfrentamento do quadro urbano e habitacional no Brasil. Nesse contexto, a aprovação da Política Nacional de Habitação (PNH) em 2004, com um conjunto de instrumentos que buscaram integrar os diferentes níveis de governo e concentrar recursos expressivos para sua concretização, estabeleceu as "novas" bases institucionais e conceituais que passaram a orientar o Estado e demais agentes envolvidos no setor, ao equacionamento das necessidades habitacionais do país.

A partir de 2005, a valorização da temática habitacional pelo governo federal, paralelamente à melhoria da conjuntura macroeconômica, permitiu impulsionar a elevação dos investimentos em programas e projetos habitacionais, conformando um cenário favorável que realçou um otimismo para o equacionamento das necessidades habitacionais do país, sobretudo com a instituição do Programa de Aceleração do Crescimento (PAC) e do Programa Minha Casa Minha Vida (PMCMV) (Bonduki, 2008).

Apesar da priorização da temática habitacional, estudos recentes evidenciam que, embora os avanços no campo das políticas urbana e habitacional acenem uma perspectiva positiva, seus resultados qualitativos indicam uma face paradoxal. A expressiva disponibilização de recursos como dimensão estratégica para financiamento, subsídio e otimização da cadeia produtiva da construção civil em nível 
federal, ao mesmo tempo em que permite alcançar parcelas populacionais de menor renda, antes não atendidas, tem como foco ampliar a participação da iniciativa privada nos processos de produção. Ao inserir o protagonismo da política de habitação em um viés de aceleração do crescimento econômico, passa-se a reproduzir um padrão de segregação socioterritorial e precariedade urbana e ambiental que retoma os erros e contradições recorrentes na trajetória histórica da política habitacional brasileira (Bonduki, 2008; Rolnik e Klink, 2011; Shimbo, 2010).

Esse novo contexto sinalizou uma perspectiva promissora para articular a questão fundiária à política habitacional. Apesar de haver um consenso de que a terra urbana é componente e condição essencial para o êxito das ações que efetivam tal política, acredita-se que as práticas habitacionais empreendidas raramente trataram desse componente de maneira adequada e pouco se questionaram sobre qual premissa se estruturariam. Busca-se, portanto, analisar como a questão fundiária para a produção de moradias é tratada e embasada no desenho das políticas nacionais de habitação.

\section{Política Nacional de Habitação: pressupostos e contradições}

A formulação da Política Nacional de Habitação (PNH) partiu da concepção de uma dívida social acumulada no país, fruto das desigualdades sociais e da concentração de renda características da sociedade brasileira, expressa na segregação socioespacial vivida no espaço das cidades e na restrição histórica do acesso a terra e à moradia por meio do mercado formal, para a população de baixa renda (MCidades, 2006).

Preconizando a gestão participativa e democrática, adotando-se o direito à moradia como direito fundamental e a moradia digna como vetor de inclusão social, a articulação com a política urbana e a integração às ações das demais políticas sociais e ambientais foram estabelecidas como princípios fundamentais da PNH (MCidades, 2006). A partir desses princípios, a gestão e o controle social, o projeto financeiro e a política fundiária urbana ficaram conceitualmente definidos como eixos centrais de sua implantação (Bonduki, 2008).

Para o eixo da política fundiária, a PNH estabeleceu como princípios a implementação dos instrumentos e das diretrizes gerais da política urbana dispostos pelo Estatuto da Cidade, visando garantir o cumprimento da função social da cidade e da propriedade, bem como o melhor ordenamento e controle do uso do solo, de forma a combater a retenção especulativa da terra e viabilizar o seu acesso pela população de baixa renda (MCidades, 2006).

Para o projeto financeiro, concebeu-se a estruturação do Sistema Nacional de Habitação (SNHAB), que passou a definir as formas de articulação entre os diferentes níveis de governo e os demais agentes públicos e privados envolvidos no setor habitacional, bem como as regras, os componentes e as linhas de atuação que direcionariam recursos para a implementação da PNH.

O SNHAB se organizou em dois subsistemas: o Sistema Nacional de Habitação de Interesse Social (SNHIS) e o Sistema Nacional de Habitação de Mercado (SNHM). O SNHM teve como objetivo garantir e sustentar a 
participação do setor privado na produção habitacional, visando ampliar a oferta e facilitar 0 acesso ao financiamento da habitação pelos setores populares não atendidos anteriormente pelo mercado. Por sua vez, o SNHIS, instituído pela Lei Federal 11.124/2005, teve como objetivos integrar os entes federativos e ampliar os recursos federais, estaduais e municipais, visando incrementar os subsídios destinados ao atendimento habitacional das faixas populacionais de baixa renda, concentradoras da maior parcela do deficit habitacional brasileiro (Bonduki, 2009; MCidades, 2006).

A regulamentação do SNHIS se articulou à criação do Fundo Nacional de Habitação de Interesse Social (FNHIS), que passou a ser gerido por um conselho correlato - o ConseIho Gestor do FNHIS. Para a implantação do Sistema e para acesso aos recursos do FNHIS, Estados, municípios e Distrito Federal foram impelidos à sua adesão mediante três requisitos: constituir fundo municipal de Habitação de Interesse Social (HIS); instituir respectivo conselho gestor paritário e com representatividade de movimentos sociais ligados à moradia; e elaborar plano de habitação em seu nível de gestão (Brasil, 2005). Para Cardoso e Aragão (2013, p. 32),

a lógica da criação do Sistema Nacional de Habitação de Interesse Social seria fortalecer os órgãos públicos municipais e estaduais para a implantação de políticas habitacionais. Os Fundos de HIS seriam os mecanismos que permitiriam aos Municípios alavancar recursos próprios e potencializar os recursos federais ou estaduais que lhes fossem repassados. Ao mesmo tempo os Conselhos Gestores dos Fundos locais promoveriam uma maior participação da sociedade civil em relação à definição sobre a alocação e ao uso dos recursos aportados para HIS.

A efetivação do SNHIS tocaria, nesse sentido, o eixo da gestão e do controle social da PNH, uma vez que permitiria um novo modelo de gestão de recursos - democrático, participativo e descentralizado - bem como a definição de estratégias de enfrentamento da problemática da habitação direcionadas às realidades locais (MCidades, 2006).

A definição de estratégias específicas estaria expressa nos planos de habitação, documentos que passariam a representar as políticas habitacionais de cada nível de governo. Os planos estariam alinhados à $\mathrm{PNH}$ a partir das diretrizes estabelecidas pelo Plano Nacional de Habitação (PLANHAB), formulado pela Secretaria Nacional de Habitação (SNH) em 2008.

0 PLANHAB procurou estabelecer propostas que considerassem a diversidade da problemática habitacional no país, as especificidades regionais e municipais, bem como as diferentes visões dos segmentos ligados ao setor da habitação (Bonduki, 2009). Como um instrumento da PNH, o PLANHAB teve como objetivo desenhar estratégias, tanto públicas quanto privadas, para o equacionamento das necessidades habitacionais brasileiras, inseridas em um horizonte temporal de quinze anos (20082023). Para que fosse possível alterar substancialmente o quadro habitacional, essas estratégias deveriam incorporar ações simultâneas de longo, médio e curto prazo, ponderando quatro eixos principais: (1) financiamento e subsídios; (2) arranjos e desenvolvimento institucional; (3) cadeira produtiva da construção civil; e (4) política fundiária urbana (MCidades, 2010). 
Para o primeiro eixo do PLANHAB, as ações estabelecidas caminharam para a instituição de um novo modelo de financiamento e subsídios, pautado na criação de um fundo garantidor de financiamentos habitacionais, que buscasse reunir diferentes fontes de recursos para equacionar a solvabilidade das demandas populacionais com alto risco de crédito - problemática considerada como um dos grandes obstáculos para enfrentamento da questão habitacional do país.

As ações relacionadas ao segundo eixo do PLANHAB - os arranjos e desenvolvimento institucional - caminharam para iniciativas de fomento à elaboração dos instrumentos de planejamento habitacional pelas diferentes esferas de governo, em especial os planos de habitação, buscando concretizar a dimensão da participação e do controle social das políticas públicas urbanas preconizada pela PNH.

Para o eixo da cadeia produtiva da construção civil, o Plano Nacional procurou estabelecer diretrizes para estimular a ampliação da produção habitacional e a modernização das técnicas construtivas, tendo como meta dinamizar processos e reduzir o custo final do produto casa. Foram também definidas diretrizes no sentido de orientar os governos locais e estaduais para a instituição de medidas que buscassem agilizar os procedimentos de aprovação e registro de empreendimentos habitacionais, bem como simplificar os processos de licenciamento.

Em relação ao eixo da política fundiária, as propostas do PLANHAB foram ao sentido de elencar diretrizes estratégicas que pudessem ser consideradas pelos governos municipais em suas políticas e ações, tendo-se dois objetivos principais: (1) "garantir acesso a terra urbanizada, legalizada e bem localizada para a provisão de HIS (unidades prontas ou lotes) na escala exigida pelas metas do PLANHAB"; e (2) "regularizar os assentamentos informais, garantindo a permanência dos moradores de baixa renda" (MCidades, 2010, p. 120).

Os eixos estratégicos do PLANHAB deveriam ser seguidos pelas demais esferas de governo, sobretudo pelos níveis municipais, considerando a descentralização das competências federativas, estabelecida pela Constituição de 1988, a partir da qual os municípios passaram a ter autonomia sobre suas políticas de desenvolvimento urbano.

Os governos de Estado, por meio de seus planos estaduais e metropolitanos, teriam 0 papel de articular propostas de ação voltadas à questão habitacional de seu território, de promover a integração entre os planos municipais de habitação e os planos de desenvolvimento regional, bem como de apoiar os governos locais na implantação de seus programas habitacionais com políticas de subsídio. Os municípios, por meio de seus Planos Locais de Habitação de Interesse Social (PLHIS), teriam a responsabilidade de levar adiante a efetivação dos pressupostos da PNH, considerando a moradia como um direito fundamental e como um vetor de inclusão social e, portanto, como um componente da política urbana (MCidades, 2010; Cardoso e Romeiro, 2008).

Cabe problematizar que as diretrizes estratégicas do PLANHAB para o eixo da política fundiária, embora devessem ser levadas a cabo nos PLHIS(s), estariam ainda associadas e dependentes de outros instrumentos de política urbana municipal, em especial dos Planos Diretores e legislações a ele complementares. As diretrizes do PLANHAB apenas orientaram os 
municípios a instituir ou regulamentar instrumentos previstos no Estatuto da Cidade, visando o cumprimento do princípio da função social referenciado na Constituição - o que extrapola o âmbito do PLHIS. Como diretriz independente e restrita apenas à formulação do PLHIS, o PLANHAB recomendou a tarefa de "dimensionar a terra necessária para a produção de HIS" (MCidades, 2010, p. 120), procedimento técnico que se articula ao entendimento do conceito de necessidades habitacionais incorporado pela $\mathrm{PNH}$.

A viabilização das ações do PLANHAB se agrupou em linhas programáticas de atendimento que buscaram estruturar programas e subprogramas voltados a: (1) integração urbana de assentamentos precários informais; (2) apoio à melhoria da unidade habitacional; (3) produção de habitação; e (4) desenvolvimento institucional. Cada linha concentrou fontes orçamentárias, estipulou demandas e regras de atendimento específicas. Em relação à linha de produção de habitação, o Programa Minha Casa Minha Vida (PMCMV) ganhou prioridade e destaque na temática habitacional, representando um forte mecanismo de implementação e alcance das metas da PNH.

Lançado pelo governo federal e regulamentado pela Lei Federal 11.977, em 2009, o PMCMV buscou como meta a construção de um milhão de casas em um ano, tendo continuidade no período 2011-2014, com o objetivo expressivo de mais dois milhões de unidades habitacionais. Em sua primeira fase, os recursos para sua concretização foram distribuídos pelas unidades federativas de forma proporcional ao deficit habitacional estimado pela Fundação João Pinheiro (FJP) para os estados brasileiros, e de acordo com as faixas salariais, estratificadas em: famílias com renda de até três salários mínimos; famílias com renda entre três e seis salários mínimos; e famílias com renda entre seis a dez salários mínimos.

Mesmo incluído no discurso de defesa da moradia digna, o PMCMV teve claros objetivos de impactar a economia por meio dos efeitos multiplicadores da indústria da construção civil e de ampliar o mercado habitacional para famílias com renda mensal de até dez salários mínimos, mantendo o desenvolvimento do setor imobiliário - que vinha experimentando uma profunda reestruturação desde 2006 - mas que começava a sentir impactos adiante da crise econômica internacional, ocorrida em 2008 (Cardoso e Aragão, 2013).

O PMCMV permitiu um quadro favorável ao desenvolvimento da política habitacional inserida no SNHM, bem como à ampliação do financiamento, passando a viabilizar linhas de crédito ao consumidor e ao produtor da habitação. Seu lançamento, no entanto, suscitou críticas diferenciadas. Por parte dos defensores e movimentos sociais envolvidos no processo de formulação da PNH, as avaliações iniciais vieram em sentido relativamente positivo, que apontavam como inédito o volume de subsídios a ser alocado na política, o que poderia gerar um atendimento efetivo à população de mais baixa renda e a diminuição do deficit habitacional (ibid., 2013). As medidas previstas no PLANHAB para o eixo da cadeia produtiva da construção civil, sobretudo a redução do custo da habitação, também foram salientadas por seus impactos positivos no acesso à habitação de interesse social e de mercado por terem sido incorporadas ao Programa (Bonduki, 2009).

Simultaneamente a tais avaliações, críticas mais negativas surgiram no sentido de 
evidenciar a ausência das demais estratégias que o PLANHAB considerou centrais no equacionamento dos problemas habitacionais, tais como os arranjos institucionais e as estratégias urbano-fundiárias. Cardoso e Aragão (2013, p. 44) reforçaram ainda oito dimensões mal equacionadas pelo PMCMV, identificadas posteriormente na literatura crítica:

(1) a falta de articulação do programa com a política urbana; (2) a ausência de instrumentos para enfrentar a questão fundiária; (3) os problemas de localização dos novos empreendimentos; (4) excessivo privilégio concedido aos setor privado; (5) a grande escala dos empreendimentos (6) a baixa qualidade arquitetônica e construtiva dos empreendimentos; (7) a descontinuidade do programa em relação ao SNHIS e a perda do controle social sobre a sua implementação; [...] (8) as desigualdades na distribuição dos recursos como fruto do modelo institucional adotado.

Para Bonduki (2009), os impactos do PMCMV também recairiam na elevação do preço da terra, visto que o tratamento incompleto de algumas das propostas do PLANHAB - em muito decorrente das competências dos entes federados - poderia gerar efeitos de grande risco no que se refere à localização dos empreendimentos, levando à repetição dos mesmos erros evidenciados no período de atuação do Banco Nacional de Habitação (BNH), quando a implantação de conjuntos habitacionais nas bordas urbanas aprofundou a problemática dos preços de terra, bem como a segregação socioespacial presente nas cidades (Silva, 1997; Rolnik, Cymbalista e Nakano, 2008).

A articulação do PMCMV a uma política fundiária por meio da aplicação de alguns dos instrumentos do Estatuto da Cidade poderia auxiliar a reverter algumas contradições e, sobretudo, garantir a "boa localização" da moradia no território (Rolnik, 2010). Contudo, a esfera federal teria possibilidades limitadas para interferir em tal postura, uma vez que a política urbana se tornou competência do município com a Constituição. Nesse sentido, o desfecho efetivo do controle sobre os impactos da localização dos empreendimentos e da elevação do preço da terra recairia sobre as decisões e capacidades institucionais locais e sobre a aplicabilidade dos instrumentos de política urbana e dos Planos Diretores municipais.

Com efeito, nos últimos anos, evidenciam-se grandes conjuntos homogêneos viabilizados pelo PMCMV, em áreas periféricas e sem infraestrutura (Ferreira, 2012). A ausência de instrumentos de controle do uso e ocupação do solo e de uma estratégia territorial integrada entre os diferentes níveis de governo, além de comprometer a viabilização de empreendimentos em áreas centrais e de impulsionar a elevação do custo da terra urbanizada, tende a comprometer o equacionamento da problemática habitacional, contrariando as próprias diretrizes e pressupostos da PNH (Rolnik e Nakano, 2009; Shimbo, 2010; Cardoso e Aragão, 2013).

Nesse panorama, tornou-se perceptível a contraposição entre o PMCMV e a PNH, que preconizara como pontos centrais de sua implementação, além do projeto financeiro, a gestão e o controle social e a aplicação de uma política fundiária urbana. A opção adotada pelo PMCMV - dadas suas metas - esteve bem mais orientada ao projeto financeiro e quantitativo da política habitacional, sobretudo à ampliação do consumo do produto habitação a partir do alargamento do financiamento, do 
que ao enfrentamento das demais dimensões estratégicas da PNH.

Tal orientação economicista teve impactos imediatos no SNHAB, tanto em relação à adesão dos entes federados, quanto na eliminação dos repasses dos recursos do FNHIS para ações de provisão habitacional e na limitação de sua atuação nas ações de urbanização de assentamentos precários e de desenvolvimento institucional (MCidades, 2013; Cardoso e Aragão, 2013).

0 exposto evidencia desequilíbrios entre as ações programáticas e os pressupostos conceituais e estratégicos estabelecidos pela PNH. Contudo, no que diz respeito à produção de HIS e sua relação com a questão fundiária urbana, observa-se que os próprios eixos estratégicos do PLANHAB poderiam também incorrer em contradições.

Para Peixoto (2011), o eixo de financiamento e subsídio, o eixo dos arranjos institucionais e o eixo da cadeia produtiva da construção civil, que se propõem, respectivamente, a resolver o problema da solvabilidade da demanda, ampliar a participação da iniciativa privada e reduzir os custos do produto casa, poderiam ser vistos como "metas que apostam no equacionamento da questão habitacional por intermédio de estruturas de produção capitalistas tradicionais" (Peixoto, 2011, p. 150). A otimização e o alargamento da produtividade com base na construção civil e na dinamização do mercado imobiliário colocam-se como uma medida política estratégica, inclusive já praticada na trajetória da política habitacional do BNH nas décadas de 1960 e 1970, que traz como premissa elevar a atividade econômica e os níveis de emprego no país - o que poderia repercutir no "erro de equiparar crescimento econômico a desenvolvimento social" (ibid., p. 150), deixando de lado os resultados negativos desse crescimento no espaço das cidades (Rolnik e Nakano, 2009).

Os aspectos desses três eixos do PLANHAB acabariam por divergir das suas próprias estratégias traçadas para a política fundiária. 0 objetivo da estratégia urbano-fundiária de garantir acesso a terra urbanizada, legalizada e bem localizada para a provisão de HIS, propõe diretrizes que consideram a aplicação de instrumentos urbanísticos para o cumprimento do princípio da função social. Em sua relação com a política habitacional, a aplicação desses instrumentos parte da premissa de se reservar e destinar áreas para o interesse social, retirando-as da disputa de capitais, o que contraria os pressupostos dos demais eixos que se pautam na estruturação capitalista da produção da moradia, na qual a terra é tida como componente essencial dos lucros (Peixoto, 2011; Silva, 1997).

Como salienta Peixoto (2011, p. 150), a não superação das divergências e contradições suscitará ainda "o risco de se incorrer num autoaniquilamento das proposições e de que as iniciativas que começam a ser esboçadas caiam no limbo dos planos que não saem do papel". A superação dessas divergências e contradições tem relação intrínseca com a dimensão fundiária da política habitacional e, portanto, com as propostas de articulação aos instrumentos de política urbana a serem estruturadas nos conteúdos estratégicos dos planos de habitação, no âmbito das diferentes esferas de governo. 


\section{Planos de habitação: conteúdos estratégicos e limitações}

No intuito de implementar a PNH e incentivar a adesão de estados e municípios ao SNHIS, a partir de 2007, o Ministério das Cidades passou a investir no apoio à elaboração dos planos de habitação e em ações de capacitação, buscando orientar equipes públicas e consultorias no desenvolvimento desses instrumentos de planejamento.

As orientações quanto aos conteúdos dos planos e as datas para adesão ao Sistema foram organizadas pela Secretaria Nacional de Habitação (SNH) e pelo Conselho Gestor do FNHIS em resoluções e cartilhas normativas, em especial no Guia de Adesão ao SNHIS (MCidades, 2008a), no Manual do FNHIS de Apoio à Elaboração de Planos Locais de Habitação de Interesse Social (ibid., 2008b) e no material do curso à distância oferecido pela SNH para elaboração de PLHIS - EAD PLHIS (ibid., 2009). Pelas diretrizes aí estabelecidas, o processo de formulação dos planos deveria ocorrer de forma participativa e em três etapas: uma etapa de Proposta Metodológica; uma etapa para realização do Diagnóstico do Setor Habitacional; e uma etapa para formulação das Estratégias de Ação a serem implementadas no horizonte temporal do planejamento habitacional.

A Proposta Metodológica deveria declarar como se daria a formulação desse planejamento: as etapas; o cronograma; os prazos e as responsabilidades das equipes de trabalho (do governo e da consultoria); as formas de participação e publicização do processo; bem como os atores sociais a serem envolvidos. Já o Diagnóstico Habitacional deveria explicitar o que seria enfrentado com a sua formulação e implementação, apresentando para tanto uma leitura crítica da realidade municipal ou regional, tendo em vista: a inserção territorial e dinâmica socioeconômica; as capacidades institucionais e administrativas para política de HIS; os recursos disponíveis e potenciais para a habitação; os atores sociais e suas capacidades de participação e controle da política urbana; a oferta habitacional; a necessidade de solo urbanizado; os marcos legais e regulatórios; e as necessidades presentes e futuras por novas moradias.

A etapa das Estratégias de Ação deveria, com base no Diagnóstico Habitacional, definir os princípios, diretrizes e objetivos do plano habitacional; as formas de sua implementação seus programas e linhas de ação; as metas físicas, financeiras, institucionais e normativas para sua aplicação; bem como seu prazo de vigência e os mecanismos para monitoramento, avaliação e revisão de suas propostas.

Assim como na $\mathrm{PNH}$, a política fundiária teria uma dimensão estratégica na formulação e implementação dos planos de habitação, cabendo a ela estabelecer as bases para a realização dos programas habitacionais no nível local, sobretudo aqueles direcionados à produção de novas moradias (MCidades, 2006). Nesse sentido, considerando as necessidades habitacionais presentes e futuras identificadas na etapa de Diagnóstico - e tendo em vista a diretriz estratégica do PLANHAB, os planos deveriam incluir informações conclusivas sobre a quantidade de terras necessárias e disponíveis no território, contemplando medidas práticas, legislativas e administrativas para sua viabilização. Tais medidas deveriam levar em conta o marco legal urbanístico, sobretudo o Plano 
Diretor, uma vez que esse passou a ser o instrumento básico da política fundiária após a promulgação do Estatuto da Cidade (Cardoso e Romeiro, 2008).

Para que fosse possível a inclusão de informações e medidas conclusivas para enfrentamento da questão fundiária, a formulação dos planos de habitação, como parte do processo de implantação da PNH, exigiu a explicitação de alguns conceitos e a definição de terminologias relativas às necessidades habitacionais e à precariedade da moradia, por parte da SNH. Como princípio, buscou-se uma uniformização de conteúdos que permitisse a construção gradual de um sistema de informações e avaliação sobre a questão habitacional em nível nacional (MCidades, 2009).

Em relação à precariedade da moradia, 0 conceito adotado pela $\mathrm{SNH}$ - referenciado no PLANHAB - procurou delimitar quatro categorias representativas do fenômeno nas áreas urbanas: (1) cortiços, (2) conjuntos habitacionais produzidos pelo poder público em situação de irregularidade ou de degradação, (3) loteamentos irregulares de moradores de baixa renda e (4) favelas. Essa delimitação serviria para aprofundar a caracterização da problemática da moradia, o que poderia levar à formulação de diretrizes e estratégias de ação e intervenção mais adequadas às características das necessidades habitacionais.

Em relação às necessidades habitacionais, a SNH procurou incorporar os três tipos de necessidades conceituadas pela Fundação João Pinheiro (FJP): (1) o deficit - representativo da necessidade de reposição total do estoque de moradias precárias e do atendimento da demanda reprimida; (2) a demanda futura entendida como a necessidade de construção de novas moradias exigidas pelo crescimento demográfico; e (3) a inadequação, representativa da necessidade de melhoria de unidades habitacionais. No âmbito da inadequação habitacional, colocam-se ainda como componentes: a carência de infraestrutura, 0 adensamento excessivo, a irregularidade da posse e da propriedade fundiária, e os domicílios com alto grau de depreciação ou sem unidade sanitária domiciliar exclusiva (MCidades, 2009).

As conceituações foram tratadas como questões essenciais a serem levantadas no âmbito da elaboração dos planos de habitação, em suas diversas escalas. 0 conhecimento das diversas precariedades e necessidades habitacionais, tanto as acumuladas ao longo do tempo como as previstas para o futuro, seria conteúdo estratégico e fundamental para a formulação de políticas alinhadas à PNH. Contudo, o próprio PLANHAB salientou para a carência de sistemas consistentes de informação e monitoramento da problemática da habitação nas diversas instâncias, as quais, em muitos casos, assumiam parâmetros desarticulados e desordenados de quantificação e qualificação das necessidades habitacionais, tornando mais complexo o desafio de enfrentá-las (ibid., 2010; Pulhez, 2012).

Com isso, como parte das iniciativas de apoio e capacitação ao desenvolvimento dos planos, a SNH indicou uma série de fontes de dados e informações, bem como métodos específicos que auxiliassem a abordagem das necessidades habitacionais, uma vez que a inconsistência dos referenciais para dimensioná-las poderia se colocar como fator complicador para a definição de programas e estratégias de ação. A recomendação de diversas fontes de dados - tais como a FJP, o Instituto Brasileiro 
de Geografia e Estatísticas (IBGE), o Centro de Estudos da Metrópole (CEM) do Cebrap (Centro Brasileiro de Análise e Planejamento), para quantificação de uma mesma problemática, levaria, contudo, à tarefa de sua compatibilização, impelindo os entes federados a tomar decisões técnicas ainda não muito experimentadas para identificar as necessidades habitacionais (Pulhez, 2012; Denaldi, Leitão e Akaishi, 2011).

Em relação aos entes estaduais, cabe registrar que outros conteúdos estratégicos foram ainda sugeridos pela SNH. Com base no papel dos Estados na política habitacional, entendido como ente articulador e integrador das ações municipais e regionais em seu território, caberia aos planos estaduais de habitação, no que diz respeito à questão fundiária: (1) o dimensionamento das necessidades fundiárias para produção de HIS; (2) a formulação de diretrizes, metas de ação, medidas e instrumentos para a regularização fundiária de assentamentos enquadrados no conceito de precariedade habitacional; e (3) a definição de mecanismos que pudessem estimular a aplicação de uma política fundiária pelos municípios para efetivação de políticas habitacionais alinhadas aos princípios da função social e da PNH (Cardoso e Romeiro, 2008). Sobre esses mecanismos de estímulo à aplicação de uma política fundiária, Cardoso e Romeiro $(2008$, p. 36) destacam como exemplo a

[...] definição de indicadores para serem considerados na pontuação como estímulo para recebimento de recursos do Fundo Estadual de Habitação de Interesse Social ou de Desenvolvimento Urbano pelos Municípios, tais como:
- Revisão do zoneamento a fim de reservar parte do território para HIS;

- Planos de Expansão com percentual de cotas para HIS;

- Plano de reparcelamento para implementação de HIS em áreas vazias consolidadas;

- Revisão da Planta Genérica de Valores com cobrança eficiente do IPTU;

- Aplicação de edificação compulsória e IPTU Progressivo no Tempo sobre áreas urbanizadas vazias;

- Identificação e demarcação das áreas ocupadas por populações de baixa renda ou comunidade tradicionais, como Zonas Especiais de Interesse Social, ou ainda interesses culturais, para a promoção de ações de regularização fundiária de interesse social;

- Ações e medidas para o desenvolvimento de uma política municipal de prevenção e mediação dos conflitos fundiários urbanos e rurais.

Os conteúdos estaduais expostos também poderiam ser detalhados no âmbito dos planos de caráter metropolitano - sobretudo de regiões onde se constata a ausência de terras disponíveis em quantidade e condições adequadas para atendimento das necessidades habitacionais de interesse social - e por meio dos quais poderia se definir propostas de ação mais abrangentes para o território regional. Além disso, assim como o PLANHAB, os planos metropolitanos e estaduais deveriam estabelecer regras específicas para distribuição regional de recursos, determinando parâmetros para os municípios, no que diz respeito ao financiamento e subsídio de recursos para HIS (ibid.). Ressalta-se, contudo, que o PLANHAB apenas recomenda tais aspectos se a insuficiência de cada município em atender suas necessidades 
isoladamente for constatada, mesmo reconhecendo a ausência de instâncias que integrem e articulem a ação de estados e municípios em regiões metropolitanas (MCidades, 2010).

Com relação aos entes municipais, os mesmos conteúdos estratégicos estabelecidos para os governos estaduais poderiam ser considerados na formulação dos planos de habitação, destacando-se, no entanto, a competência municipal de se legislar sobre a política urbana. Por essa competência, os planos locais de HIS teriam um papel mais efetivo no que se refere ao alcance dos princípios e objetivos da PNH. Esse alcance estaria vinculado à sua articulação ou às propostas de análise e revisão da legislação urbana municipal, em especial os Planos Diretores, haja vista as limitações conhecidas desses Planos e o curto alcance dos instrumentos urbanísticos do Estatuto da Cidade, evidenciados nos levantamentos organizados por Santos Jr. e Montandon (2011). Nesse sentido, a depender do grau de abrangência do Plano Diretor, a forma como se daria o alinhamento da habitação com a questão fundiária poderia repercutir na inviabilização da terra para os programas de produção de novas moradias por meio de estratégias urbano-fundiárias, como preconizado pela PNH e pelo PLANHAB.

Cabe destacar que o conteúdo dos planos habitacionais foi apresentado nas cartilhas e resoluções do Ministério das Cidades para todos os entes federados, indiferentemente de seu porte populacional ou estágio de desenvolvimento institucional. Contudo, as constantes necessidades de adaptação do governo federal às dificuldades encontradas principalmente pelos gestores municipais, em especial dificuldades técnicas na elaboração dos PLHIS, levaram o Conselho Gestor do FNHIS a prorrogar sucessivamente os prazos para adesão ao SNHIS e para a finalização dos planos. Nessas adaptações, o Conselho do FNHIS passou a incluir a possibilidade de elaboração da forma simplificada do Plano (PLHIS Simplificado), pensada para municípios com população de até 50 mil habitantes.

Para Denaldi, Leitão e Akaishi (2011), as alterações em relação às exigências de adesão ao SNHIS estariam relacionadas tanto a fragilidades institucionais locais, quanto à falta de uma cultura de planejamento habitacional, o que revela ainda a permanente necessidade de capacitação técnica das instâncias administrativas locais. Para Cardoso e Aragão (2013), de todo modo a lógica de implementação do SNHIS exigiria o fortalecimento da esfera pública local e a "necessidade da construção de uma nova cultura política e de novos mecanismos institucionais para as ações de política urbana e habitacional" (Cardoso e Aragão, 2013, p. 32).

Acrescenta-se também nesse debate 0 fato de muitos municípios terem encontrado dificuldades nos processos participativos de formulação dos PLHIS e na composição dos Conselhos de Habitação (MCidades, 2013). Os Conselhos teriam papel fundamental na continuidade das propostas dos planos habitacionais e em sua articulação com a política urbana, em razão de suas funções estruturais na gestão dos recursos dos fundos municipais e na participação e controle social.

A partir do lançamento do PMCMV, houve ainda uma relativa retração do SNHIS, o que reduziu fortemente os ritmos de adesão e conclusão dos planos pelos entes federados. Com exceção dos estados e Distrito Federal - que cumpriram inteiramente as 
exigências estabelecidas, a maioria dos municípios acabou efetivando sua adesão na fase inicial de funcionamento do Sistema, entre 2006 e 2008. Já a elaboração dos PLHIS(s), a conclusão média do Brasil, entre 2007 e 2013 havia abrangido mais de 2.900 cidades, o correspondente a $52,6 \%$ do total de municípios do país (MCidades, 2013).

Mesmo diante do contexto paralelo do PMCMV e das dificuldades na formulação dos PLHIS(s) e na implementação do SNHIS, a esfera federal apostava que a elaboração dos planos de habitação serviria não apenas para a viabilização da adesão ao Sistema Nacional, como também para tornar as demais esferas de governo conscientes de suas problemáticas habitacionais e das capacidades institucionais existentes para seu enfrentamento (ibid., 2009).

Embora a dimensão fundiária da PNH e o marco regulatório urbanístico, representado pela Constituição Federal e pelo Estatuto da Cidade, não garantissem a efetividade no equacionamento das problemáticas habitacionais - uma vez que os resultados efetivos dependeriam de ações conclusivas e de decisões políticas pautadas no princípio da função social da terra -, a esfera federal apostava que, com a adesão ao SNHIS, ficariam estabelecidas, ao menos em tese, as condições normativas, institucionais e os pressupostos conceituais que permitiriam avanços na questão habitacional no país nas diferentes escalas territoriais.

Diante do desenho das políticas, programas e planos destaca-se, no entanto, que a problemática fundiária ainda foi pouco enfatizada ou tratada de forma básica. Isso porque, enquanto as ações dos municípios sobre a questão fundiária da política habitacional passam pela formulação dos Planos Diretores e dos Planos Locais de Habitação - permitindo a adoção dos instrumentos urbanísticos do Estatuto da Cidade, bem como a compatibilização de estratégias de acesso e gestão social da terra -, as ações de produção habitacional priorizadas em nível federal com o PMCMV passam pela elevação dos financiamentos e subsídios sem qualquer vinculação aos instrumentos de planejamento municipal (Buonfiglio e Bastos, 2011). Há, nesse sentido, uma sobreposição conflitante entre as atuações das diferentes esferas de governo diante das diretrizes e pressupostos da PNH, bem como as metas do referido Programa e, no que tange, em especial, a questão fundiária.

\section{Considerações finais}

Com base na caracterização do marco de fundamentação da PNH, evidenciam-se desequilíbrios entre suas dimensões estratégicas e ações programáticas, no que diz respeito à relação entre a questão fundiária e a produção habitacional.

A expressiva disponibilização de recursos como dimensão estratégica para financiamento, subsídio e otimização da cadeia produtiva da construção civil em nível federal, ao mesmo tempo em que permite alcançar parcelas populacionais de menor renda, antes não atendidas, tem como foco ampliar a participação da iniciativa privada nos processos de produção. Com isso, aposta no equacionamento da problemática habitacional por meio de estruturas privadas de obtenção da terra para a política pública. Nessas estruturas, os lucros e os gastos fundiários têm peso significativo, o que coloca 
a terra urbana na linha de disputa de capitais, contrariando a dimensão estratégica de aplicação de uma política de solo que tenha como viés o controle social da apropriação da terra e a garantia de localizações que qualifiquem 0 acesso aos benefícios do processo formal de urbanização para a população de baixa renda. Eis uma tarefa fundamental para novas pesquisas sobre a temática fundiária: como fortalecer a questão fundiária como objeto de controle social ao invés de permanecer como instrumento de disputa de capitais. Somente sobre essa premissa conseguir-se-ia pautar, mas profundamente, a questão fundiária e dar luz a políticas efetivas e inclusivas.

Apesar das novas políticas tornarem possível conceber um discurso que levaria a considerar a inclusão de uma nova política fundiária na política de habitação nacional, a PNH cai em erros semelhantes aos praticados no passado da política habitacional, nos quais as ações de produção de moradias não foram acompanhadas de políticas de solo redistributivas, mas, sim, foram fortemente influenciadas pela problemática fundiária, tendo contribuído para aprofundar o quadro de precariedade e segregação socioespacial nas cidades.

Nesse sentido, ao mesmo tempo em que se assiste a estruturação e valorização de um discurso fundamentado de política nacional de habitação, evidencia-se o enfraquecimento precoce dessa estrutura institucionalizada em prol de uma política de aceleração do crescimento econômico, pautada por um programa que se desvincula de seu pressuposto gerador.

Ainda que a estrutura da política nacional possa ser descentralizada e venha a delegar às esferas estadual e municipal o papel executor de suas ações, a esfera federal exerce papel fundamental no comando, na coordenação e na regulação de suas políticas territoriais, de forma que as prioridades de estados e municípios passam a ser profundamente condicionadas por suas metas e diretrizes. Sob tal aspecto, a ausência de uma estratégia fundiária integrada entre os diferentes níveis de governo para a política habitacional corrobora não apenas para que os subsídios públicos disponibilizados sejam transferidos à especulação imobiliária, mas para o agravamento da questão fundiária urbana.

Esse olhar sobre o desenho das políticas habitacionais, suas engrenagens e incongruências, indica a urgência de novos aprofundamentos sobre o papel fundiário nas políticas habitacionais e sua premissa básica - de controle social, para não recair no dilema de práticas fundiárias em que a questão da terra urbana se mantém na linha de disputa de capitais. Estudos sobre a elaboração e implementação dos PLHIS contribuiriam, por exemplo, para desvendar o papel dado a terra urbana, bem como compreender como a questão fundiária foi tratada. 


\section{Tomás Antonio Moreira}

Universidade de São Paulo, Instituto de Arquitetura e Urbanismo. São Carlos/SP, Brasil.

tomas_moreira@sc.usp.br

\section{Joana Aparecida Z. M. T. Ribeiro}

Universidade Paulista, Instituto de Ciências Exatas e Tecnologia, Faculdade de Arquitetura e Urbanismo. Jundiaí/SP, Brasil.

joana.zavagliaribeiro@gmail.com

\section{Referências}

BONDUKI, N. (2008). Política habitacional e inclusão social no Brasil: revisão histórica e novas perspectivas no governo Lula. Revista eletrônica de Arquitetura e Urbanismo. São Paulo, n. 1, pp. 70-104.

(2009). Do Projeto Moradia ao Programa Minha Casa Minha Vida. Teoria e Debate, v. 82, p. 1.

(2011). O modelo de desenvolvimento urbano de São Paulo precisa ser revertido. Estudos avançados. São Paulo, v. 25, n. 71, pp. 23-36.

BRASIL (2001). Lei no 10.257, de 10 de julho. Estabelece diretrizes gerais da política urbana. Diário Oficial da União. Brasília-DF.

(2005). Lei no 11.124, de 16 de junho. Dispõe sobre o Sistema Nacional de Habitação de Interesse Social - SNHIS, cria o Fundo Nacional de Habitação de Interesse Social - FNHIS e institui o Conselho Gestor do FNHIS. Diário Oficial da União. Brasília-DF.

(2009). Lei no 11.977, de 7 de julho. Dispõe sobre o Programa Minha Casa Minha Vida - PMCMV e a regularização fundiária de assentamentos localizados em áreas urbanas. Diário Oficial da União. Brasília-DF.

BUONFIGLIO, L. V. e BASTOS, R. D. (2011). O lugar das políticas de habitação popular nas cidades brasileiras. In: XII SIMPÓSIO NACIONAL DE GEOGRAFIA. Anais. Belo Horizonte, UFMG.

CARDOSO, A. e ARAGÃO, T. (2013). “Do fim do BNH ao Programa Minha Casa Minha Vida: 25 anos da política habitacional no Brasil". In: CARDOSO, A. (org.). O Programa Minha Casa Minha Vida e seus efeitos territoriais. Rio de Janeiro, Letra Capital.

CARDOSO, P. e ROMEIRO, P. (2008). Sistema Nacional de Habitação de Interesse Social à luz do novo marco legal urbanístico: subsídios para implementação nos estados e municípios - Lei Federal no 11.125/05. São Paulo, Instituto Pólis.

DENALDI, R.; LEITÃO, K. e AKAISHI, A. (2011). O recente processo de elaboração dos Planos Locais de Habitação de Interesse Social no Brasil: limitações e perspectivas. In: XIV ENCONTRO NACIONAL DA ANPUR. Anais. Rio de Janeiro, Anpur. 
FERREIRA, J. S. W. (2012). Produzir casas ou construir cidades? Desafios para um novo Brasil urbano. São Paulo, LABHAB/Fupam.

MCIDADES, MINISTÉRIO DAS CIDADES (2006). Cadernos MCidades: Política Nacional de Habitação. Brasília, n. 4.

(2008a). Guia de Adesão ao Sistema Nacional de Habitação de Interesse Social-SNHIS. Brasília, Ministério das Cidades/Secretaria Nacional de Habitação.

(2008b). Manual para apresentação de Propostas. Apoio à Elaboração de Planos Habitacionais de Interesse Social. Brasília, Ministério das Cidades/Secretaria Nacional de Habitação/Fundo Nacional de Habitação de Interesse Social.

(2009). Curso à distância: Planos Locais de Habitação de Interesse Social. Brasília, Ministério das Cidades/Secretaria Nacional de Habitação.

(2010). Plano Nacional de Habitação - versão para debates. Brasília, Ministério das Cidades/ Secretaria Nacional de Habitação.

(2013). Relatório de Gestão do exercício 2012. Brasília, Ministério das Cidades/Secretaria Nacional de Habitação/ Fundo Nacional de Habitação de Interesse Social. Disponível em: http:// www.cidades.gov.br/index.php/conselho-gestor-fnhis/prestacao-de-conta. Acesso em: 3 jun 2013.

MOREIRA, T. A. (2012). Falta o falsa política habitacional y del suelo. Ciudades. Puebla/México, n. 95, pp. 39-46.

PEIXOTO, A. P. M. (2011). Vacância residencial na Região Metropolitana de Belo Horizonte: mobilização do estoque vago para a promoção de habitação de interesse social. Dissertação de Mestrado. Belo Horizonte, Universidade Federal de Minas Gerais.

PULHEZ, M. M. (2012). Plano de habitação, produção de habitação: as fronteiras de conflito da política pública - considerações a partir do caso da cidade de São Carlos (SP). Revista Brasileira de Estudos Urbanos e Regionais, v. 14, n. 1, pp. 99-117.

ROLNIK, R. (org.). (2010). Como produzir moradia bem localizada com os recursos Programa Minha Casa, Minha Vida? Implementando os instrumentos do Estatuto da Cidade. Brasília, Ministério das Cidades.

ROLNIK, R.; CYMBALISTA, R. e NAKANO, K. (2008). Solo urbano e habitação de interesse social: a questão fundiária na política habitacional e urbana do país. Disponível em: http://raquelrolnik. files.wordpress.com/2013/04/solo-urbano-e-his-rolnik-nakano-cymbalista.pdf. Acesso em: 23 maio 2014.

ROLNIK, R. e KLINK, J. (2011). Crescimento econômico e desenvolvimento urbano: por que nossas cidades continuam tão precárias? Revista Novos Estudos Cebrap, n. 89, pp. 89-109.

ROLNIK, R. e NAKANO, K. (2009). As armadilhas do pacote habitacional. Le Monde Diplomatique. Brasil, seção Moradia, pp. 4-5. Disponível em: http://www.diplomatique.org.br/artigo.php?id=461. Acesso em: 21 maio 2014. 
SANTOS JR., O. A. dos e MONTANDON, D. T. (orgs.) (2011). Os Planos Diretores municipais Pós-Estatuto da Cidade: balanço crítico e perspectivas. Rio de Janeiro, Letra Capital/Observatório das Metrópoles/ Ippur/UFRJ.

SHIMBO, L. Z. (2010). Habitação social, habitação de mercado: a confluência entre Estado, empresas construtoras e capital financeiro. Tese de Doutorado. São Paulo, Universidade de São Paulo.

SILVA, H. M. B. (1997). Terra e moradia: que papel para o município? Tese de Doutorado. São Paulo, Universidade de São Paulo.

Texto recebido em 2/jun/2015

Texto aprovado em 14/set/2015 
